\title{
Frailty defined by FRAIL scale as a predictor of mortality: A systematic review and meta-analysis
}

Gotaro Kojima, $\mathrm{MD}^{1}$.

${ }^{1}$ Department of Primary Care and Population Health, University College London, London, UK

Corresponding Author:

Gotaro Kojima, MD

Department of Primary Care and Population Health

University College London (Royal Free Campus)

Rowland Hill Street,

London, NW3 2PF, UK

Phone: +44 (0)20 77940500

Fax: $+44(0) 2074726871$

Email: gotarokojima@yahoo.co.jp

\begin{abstract}
Objectives: To conduct a systematic review of the literature on prospective cohort studies examining mortality risk according to frailty defined by FRAIL scale, and to perform a metaanalysis to synthesize the pooled risk estimates.
\end{abstract}

Design: Systematic review and meta-analysis.

Setting: Embase, Scopus, MEDLINE, CINAHL, and PsycINFO were systematically searched in January 2018. References of included studies were reviewed and a forward citation tracking was performed on relevant review papers for additional studies. Additional data necessary for a meta-analysis were requested to corresponding authors.

Participants: Community-dwelling middle-aged and older people.

Measurements: Mortality risk according frailty defined by FRAIL scale.

Results: After removing duplicates, there are 81 citations for title, abstract, and full-text screening. Eight studies were included in this review. Four studies calculated area under the receiver operating characteristic curve, which ranged from 0.54-0.70. A random-effects metaanalysis was conducted on three studies that provided adjusted hazard ratios (HR) of mortality risk according to three frailty groups (robust, prefrail, and frail) defined by FRAIL scale. Both frailty and prefrailty were significantly associated with higher mortality risk than robustness (pooled $\mathrm{HR}=3.53,95 \% \mathrm{CI}=1.66-7.49, \mathrm{p}=0.001$; pooled $\mathrm{HR}=1.75,95 \% \mathrm{CI}=1.14$ $270, p=0.01$, respectively). No evidence of publication bias was observed.

Conclusion: This study demonstrated that FRAIL scale is a tool that can effectively identify frailty/prefrailty status, as well as quantify frailty status in a graded manner in relation to mortality risk. Although its feasibility is of note, not many studies are yet using this relatively new tool. More studies are warranted regarding mortality and other health outcomes.

Keywords: Frailty; FRAIL scale; Mortality; Systematic review; Meta-analysis. 


\section{INTRODUCTION}

Frailty is a state of decreased physiological reserve and increased vulnerability to negative health outcomes. ${ }^{1,2}$ Frailty is associated with falls, ${ }^{3}$ fractures, ${ }^{4}$ hospitalization, ${ }^{5}$

institutionalization, ${ }^{6}$ disabilities, ${ }^{7}$ lower quality of life, ${ }^{8}$ dementia, ${ }^{9}$ and premature death. ${ }^{10}$ Although there have been a numerous definitions and criteria proposed in the literature for determining frailty, consensus has yet to be reached. ${ }^{1}$ The International Association of Nutrition and Aging Task Force proposed a new frailty tool, the FRAIL scale, based on five components: Fatigue, Resistance (inability to climb stairs), Ambulation (inability to walk a certain distance), Illnesses, and Loss of weight. ${ }^{11}$ FRAIL scale is a quick and simple questionnaire consisting of only five self-reported YES/NO items. ${ }^{12}$ It does not require special equipment or measurements and therefore it can be administered by phone or mail. Since its publication in $2008,{ }^{11}$ this tool has been validated in various populations and has been increasingly used in clinical and research settings. ${ }^{13}$ However, no meta-analysis has been found in the literature on associations between FRAIL scale and mortality. The aim of this study is to perform a systematic review and meta-analysis regarding frailty defined by FRAIL scale as a predictor of mortality.

\section{METHOD}

A protocol was developed according to the PRISMA statements ${ }^{14}$ and registered at PROSPERO.$^{15}$ Embase, Scopus, MEDLINE, CINAHL, and PsychINFO were searched in March 2018 for studies published later than 2008, when the FRAIL scale was first published. ${ }^{11,12}$ A combination of Medical Subjective Headings and text words related to FRAIL scale and mortality was used (available at the PROSPERO ${ }^{15}$ ). References in the included studies were reviewed, and forward citation tracking was performed for the papers advocating FRAIL scale ${ }^{1,11,12}$ using Google Scholar. Any prospective studies that examined mortality risk according to FRAIL scale among general cohorts of community-dwelling middle-aged and older people were considered potentially eligible. Studies were assessed for methodological quality using the Newcastle-Ottawa scale. ${ }^{16}$ Adequate quality studies were defined as those meeting $\geq 5$ items out of nine. If the same cohort was used by multiple studies, the study with the largest sample size was included. A meta-analysis was conducted when three or more studies provided the same effect measures (hazard ratio (HR) or odds ratio (OR)) for all-cause mortality according to categories of robust, prefrail, and frail, which were defined as having 0, 1-2, and 3-5 items of FRAIL scale, respectively. ${ }^{17}$ A random-effects meta-analysis was used due to expected high heterogeneity. Heterogeneity was measured using $\mathrm{I}^{2}$ statistic. Publication bias was assessed by visually inspecting funnel plots. Subgroup and sensitivity analyses were also attempted if possible. All analyses were performed using Review Manager 5 (Cochrane Collaboration, Denmark).

\section{RESULTS}

Figure 1 is a flowchart of the literature search. A total of 189 citations were identified from five electronic databases and 3 studies were found from other sources. After removing 111 duplicates, 81 studies remained, among which eight studies were included in this review. ${ }^{13,18-}$ ${ }^{24}$ Study characteristics and findings were summarized in Table 1. All eight studies were considered to have adequate methodological quality based on the Newcastle-Ottawa scale (range $=5-8$ ).

Four studies calculated area under the receiver operating characteristic curve (AUC), ${ }^{20-23}$ which ranged from $0.54-0.70$, most of which were statistically significantly better than by chance. Five studies used Cox proportional hazard regression models and provided hazard ratios for mortality risk according to frailty status, which was categorized, based on the 
FRAIL scale, into: 3 groups $(0,1-2,3-5),{ }^{19,20} 5$ groups $(0,1,2,3,4-5),{ }^{13,24}$ or 2 groups (unknown cut-point). ${ }^{18}$ Despite the different cut-points used, greater frailty status was significantly associated with higher mortality risks in a dose-response manner in all studies. Similar findings were shown by another study using OR. ${ }^{21}$

With additional data provided by the author on request, ${ }^{18}$ a total of three studies $(\mathrm{N}=9273)$ were used for a meta-analysis. ${ }^{18-20}$ As expected high degree of heterogeneity was observed $\left(\mathrm{I}^{2}=64-79 \%\right)$. Figure 2 presents forest plots showing the both frailty and prefrailty were significantly associated with higher mortality risk than robustness (pooled $\mathrm{HR}=3.53$, $95 \% \mathrm{CI}=1.66-7.49, \mathrm{p}=0.001$; pooled $\mathrm{HR}=1.75,95 \% \mathrm{CI}=1.14-270, \mathrm{p}=0.01$, respectively). Obvious asymmetry was not observed in the funnel plots, which suggests no evidence of publication bias.

\section{DISCUSSION}

This systematic review identified eight original studies examining frailty defined by FRAIL scale and mortality among community-dwelling middle-aged and older people. The metaanalysis, which included 9273 individuals from three studies provided evidence of the significant association between FRAIL scale-defined frailty and higher mortality.

Currently, the most commonly used frailty definitions would include the frailty phenotype and the Frailty Index. ${ }^{1}$ However, these two tools are time-consuming and practically infeasible in a busy clinical setting. The phenotypic approach requires performance measurements (gait speed and grip strength) and some calculation of lowest 20 percentile in the population examined. ${ }^{25}$ The Frailty Index requires collecting a number of deficits, typically more than $30-40 .{ }^{26}$ In contrast, FRAIL scale includes only five simple questions and can be administered in minimal time by busy clinicians, as well as other healthcare providers. $^{1,11,12}$

FRAIL scale shares similarities with the frailty phenotype in that both use five criteria and can define robust, prefrail, and frail status as meeting $0,1-2$, and 3-5 criteria, respectively. A previous meta-analysis pooled 14 studies and showed that frail and prefrail individuals were at a significantly higher mortality risk than the robust (pooled $\mathrm{HR}=2.00,95 \% \mathrm{CI}=1.73-2.32$; pooled $\mathrm{HR}=1.34,95 \% \mathrm{CI}=1.26-1.41$, respectively), ${ }^{27}$ which is in line with findings of the current study. It is not possible to compare magnitudes of the risk estimates because of the current study's wide confidence intervals resulting from the small number of the included studies.

This study is not without limitations. Partially because FRAIL scale was proposed relatively recently, ${ }^{11,12}$ only a limited number of studies were included, especially for meta-analysis. This, in turn, hinders additional analyses, including sensitivity, subgroup, or meta-regression analyses. The whole process of systematic review was conducted by one investigator (GK), and some studies may have been missed.

\section{Conclusion}

This study demonstrated preliminary evidence that FRAIL scale is a promising tool that can effectively identify frailty/prefrailty status, as well as quantify frailty status in a graded manner in relation to mortality risk. Although its feasibility is of note, not many studies are yet using this relatively new tool. More studies are warranted regarding mortality and other health outcomes. 


\section{ACKNOWLEGMENT}

\section{Conflict of Interest}

The author has no conflicts in the cover letter as well as in the manuscript, as noted above.

\section{Author Contributions}

Study concept and design: GK. Acquisition of data: GK. Analysis and interpretation of data:

GK. Drafting the article: GK. Revising the article critically for important intellectual content:

GK. Final approval of the version to be published: GK.

\section{Sponsor's Role}

None

\section{REFERENCES}

1. Morley JE, Vellas B, van Kan GA, et al. Frailty consensus: a call to action. Journal of the American Medical Directors Association 2013;14:392-397.

2. Clegg A, Young J, Iliffe S, et al. Frailty in elderly people. Lancet (London, England) 2013;381:752-762.

3. Kojima G. Frailty as a Predictor of Future Falls Among Community-Dwelling Older People: A Systematic Review and Meta-Analysis. Journal of the American Medical Directors Association 2015;16:1027-1033.

4. Kojima G. Frailty as a predictor of fractures among community-dwelling older people: A systematic review and meta-analysis. Bone 2016;90:116-122.

5. Kojima G. Frailty as a predictor of hospitalisation among community-dwelling older people: a systematic review and meta-analysis. Journal of epidemiology and community health 2016;70:722-729.

6. Kojima G. Frailty as a Predictor of Nursing Home Placement Among CommunityDwelling Older Adults: A Systematic Review and Meta-analysis. Journal of geriatric physical therapy (2001) 2018;41:42-48.

7. Kojima G. Frailty as a predictor of disabilities among community-dwelling older people: a systematic review and meta-analysis. Disability and rehabilitation 2017;39:1897-1908.

8. Kojima G, Iliffe S, Jivraj S, Walters K. Association between frailty and quality of life among community-dwelling older people: a systematic review and meta-analysis. Journal of epidemiology and community health 2016;70:716-721.

9. Kojima G, Taniguchi Y, Iliffe S, Walters K. Frailty as a Predictor of Alzheimer Disease, Vascular Dementia, and All Dementia Among Community-Dwelling Older People: A Systematic Review and Meta-Analysis. Journal of the American Medical Directors Association 2016;17:881-888.

10. Kojima G, Iliffe S, Walters K. Frailty index as a predictor of mortality: a systematic review and meta-analysis. Age and ageing 2018;47:193-200.

11. Abellan van Kan G, Rolland Y, Bergman H, et al. The I.A.N.A Task Force on frailty assessment of older people in clinical practice. The journal of nutrition, health $\&$ aging 2008;12:29-37.

12. Abellan van Kan G, Rolland YM, Morley JE, Vellas B. Frailty: toward a clinical definition. Journal of the American Medical Directors Association 2008;9:71-72.

13. Susanto M, Hubbard RE, Gardiner PA. Validity and Responsiveness of the FRAIL Scale in Middle-Aged Women. Journal of the American Medical Directors Association 2018;19:65-69.

14. Moher D, Liberati A, Tetzlaff J, Altman DG. Preferred reporting items for systematic reviews and meta-analyses: the PRISMA statement. BMJ (Clinical research ed.) 
2009;339:b2535.

15. Kojima G. The FRAIL scale as a predictor of mortality: a systematic review and meta-analysis. 2018;

https://www.crd.york.ac.uk/PROSPERO/display_record.php?RecordID=91519.

16. Wells GA, Shea D, O'Connell D, et al. The Newcastle-Ottawa Scale (NOS) for assessing the quality of nonrandomised studies in meta-analyses. http://www.ohri.ca/programs/clinical_epidemiology/oxford.asp. Accessed 20th August, 2015.

17. Morley JE, Malmstrom TK, Miller DK. A simple frailty questionnaire (FRAIL) predicts outcomes in middle aged African Americans. The journal of nutrition, health \& aging 2012;16:601-608.

18. Papachristou E, Wannamethee SG, Lennon LT, et al. Ability of Self-Reported Frailty Components to Predict Incident Disability, Falls, and All-Cause Mortality: Results From a Population-Based Study of Older British Men. Journal of the American Medical Directors Association 2017;18:152-157.

19. Diaz de Leon Gonzalez E, Gutierrez Hermosillo H, Martinez Beltran JA, et al. Validation of the FRAIL scale in Mexican elderly: results from the Mexican Health and Aging Study. Aging clinical and experimental research 2016;28:901-908.

20. Ravindrarajah R, Lee DM, Pye SR, et al. The ability of three different models of frailty to predict all-cause mortality: results from the European Male Aging Study (EMAS). Archives of gerontology and geriatrics 2013;57:360-368.

21. Malmstrom TK, Miller DK, Morley JE. A comparison of four frailty models. Journal of the American Geriatrics Society 2014;62:721-726.

22. Theou O, Brothers TD, Mitnitski A, Rockwood K. Operationalization of frailty using eight commonly used scales and comparison of their ability to predict all-cause mortality. Journal of the American Geriatrics Society 2013;61:1537-1551.

23. Woo J, Leung J, Morley JE. Comparison of frailty indicators based on clinical phenotype and the multiple deficit approach in predicting mortality and physical limitation. Journal of the American Geriatrics Society 2012;60:1478-1486.

24. Hyde Z, Flicker L, Almeida OP, et al. Low free testosterone predicts frailty in older men: the health in men study. The Journal of clinical endocrinology and metabolism 2010;95:3165-3172.

25. Fried LP, Tangen CM, Walston J, et al. Frailty in older adults: evidence for a phenotype. The journals of gerontology. Series A, Biological sciences and medical sciences 2001;56:M146-156.

26. Searle SD, Mitnitski A, Gahbauer EA, et al. A standard procedure for creating a frailty index. BMC geriatrics 2008;8:24.

27. Chang SF, Lin PL. Frail phenotype and mortality prediction: a systematic review and meta-analysis of prospective cohort studies. International journal of nursing studies 2015;52:1362-1374. 
Table 1. Characteristics of the included studies examining FRAIL scale and mortality risk among community-dwelling middle-aged and older people.

\begin{tabular}{|c|c|c|c|c|c|c|c|}
\hline Author/Year/Study & Location & $\begin{array}{l}\text { Sample } \\
\text { size }\end{array}$ & $\begin{array}{l}\text { Female } \\
(\%)\end{array}$ & $\begin{array}{c}\text { Age } \\
\text { (range) }\end{array}$ & $\begin{array}{c}\text { Follow-up } \\
\text { period }\end{array}$ & Adjustment & $\begin{array}{c}\text { Risk estimate } \\
\text { HR/OR }(95 \% \mathrm{CI})\end{array}$ \\
\hline $\begin{array}{l}\text { Susanto } 2018 \\
\text { ALSWH }\end{array}$ & Australia & 8933 & $100 \%$ & - & 16 years & $\begin{array}{l}\text { age, BMI, education, income management, } \\
\text { physical activity }\end{array}$ & $\begin{array}{l}0: \text { ref } \\
1: \mathrm{aHR}=1.07(0.83-1.37) \\
2: \mathrm{aHR}=1.64(1.19-2.27) \\
3: \mathrm{aHR}=2.01(1.29-8.23) \\
4-5: \mathrm{aHR}=4.20(2.14-8.23) \\
0-2: \text { ref } \\
3-5: \mathrm{aHR}=2.01(1.40-2.87)\end{array}$ \\
\hline $\begin{array}{l}\text { Papachristou } 2017 \\
\text { BRHS }\end{array}$ & UK & 1615 & $0 \%$ & $(71-92)$ & 3 years & age & $\begin{array}{l}0: \text { ref } \\
1-2: a H R=2.64(1.11-6.28), p=0.0 \\
3-5: a H R=7.60(3.15-18.31), p<0.001\end{array}$ \\
\hline $\begin{array}{l}\text { González } 2016 \\
\text { MHAS }\end{array}$ & Mexico & 4729 & $53.4 \%$ & $\geq 60$ & 2.4 years & $\begin{array}{l}\text { age, gender, depressive symptoms, } \\
\text { cognition, ADL }\end{array}$ & $\begin{array}{l}0: \text { ref } \\
1-2: \mathrm{aHR}=1.25(0.90-1.75), \mathrm{p}=0.18 \\
3-5: \mathrm{aHR}=1.86(1.21-2.88), \mathrm{p}=0.005\end{array}$ \\
\hline $\begin{array}{l}\text { Malmstrom } 2014 \\
\text { AAH }\end{array}$ & US & 779 & - & $(49-65)$ & 9 years & age, gender & $\begin{array}{l}\text { 0: ref } \\
\text { 1-2: } \mathrm{aOR}=1.45(0.94-2.23), \mathrm{p}=0.09 \\
3-5: \mathrm{aOR}=3.24(1.62-6.47), \mathrm{p}<0.001 \\
\mathrm{AUC}=0.57(0.51-0.62)\end{array}$ \\
\hline $\begin{array}{l}\text { Ravindrarajah } 2013 \\
\text { EMAS }\end{array}$ & $\begin{array}{l}8 \text { European } \\
\text { countries* }\end{array}$ & 2929 & $0 \%$ & 59.9 & 4.3 years & age, center, smoking, partner status & $\begin{array}{l}0: \text { ref } \\
1-2: \mathrm{aHR}=2.08(1.47-2.95) \\
3-5: \mathrm{aHR}=3.87(2.25-6.66) \\
\mathrm{AUC}=0.66(0.62-0.70)\end{array}$ \\
\hline $\begin{array}{l}\text { Theou } 2013 \\
\text { SHARE }\end{array}$ & $\begin{array}{l}11 \text { European } \\
\text { countries } * *\end{array}$ & 27527 & $54.8 \%$ & $\begin{array}{c}65.3 \\
(50-104)\end{array}$ & $\begin{array}{l}2 \text { years } \\
5 \text { years }\end{array}$ & - & $\begin{array}{l}\mathrm{AUC}=0.70(0.67-0.72) \\
\mathrm{AUC}=0.67(0.65-0.68)\end{array}$ \\
\hline Woo 2012 & China & $\begin{array}{l}2000 \\
2000 \\
\end{array}$ & $\begin{array}{c}100 \% \\
0 \% \\
\end{array}$ & $\geq 65$ & 4 years & - & $\begin{array}{l}\mathrm{AUC}=0.544(0.492-0.597) \\
\mathrm{AUC}=0.543(0.508-0.577)\end{array}$ \\
\hline $\begin{array}{l}\text { Hyde } 2010 \\
\text { HIMS }\end{array}$ & Australia & 3616 & $0 \%$ & $\begin{array}{c}76.9 \\
(70-88)\end{array}$ & 7 years & $\begin{array}{l}\text { age, BMI, hypertension, dyslipidemia, } \\
\text { diabetes, Charlson's index, smoking. }\end{array}$ & $\begin{array}{l}0: \text { ref } \\
1: a H R=1.38(1.07-1.78), p=0.01 \\
2: a H R=2.00(1.53-2.63), p<0.001 \\
3: a H R=2.27(1.70-3.04), p<0.001 \\
4-5: a H R=3.97(2.89-5.45), p<0.001\end{array}$ \\
\hline
\end{tabular}


AAH: African American Health

ALSWH: Australian Longitudinal Study on Women's Health

BRHS: British Regional Heart Study

EMAS: European Male Aging Study

HIMS: Health in Men Study

MHAS: Mexican Health and Aging Study

SHARE: Survey of Health, Ageing and Retirement in Europe

* Belgium, Estonia, Hungary, Italy, Poland, Spain, Sweden, UK

** Italy, Belgium, Denkarm, France, Germany, Greece, Italy, Netherlands, Spain, Sweden, Switzerland. 
Figure 1. PRISMA Flow chart.

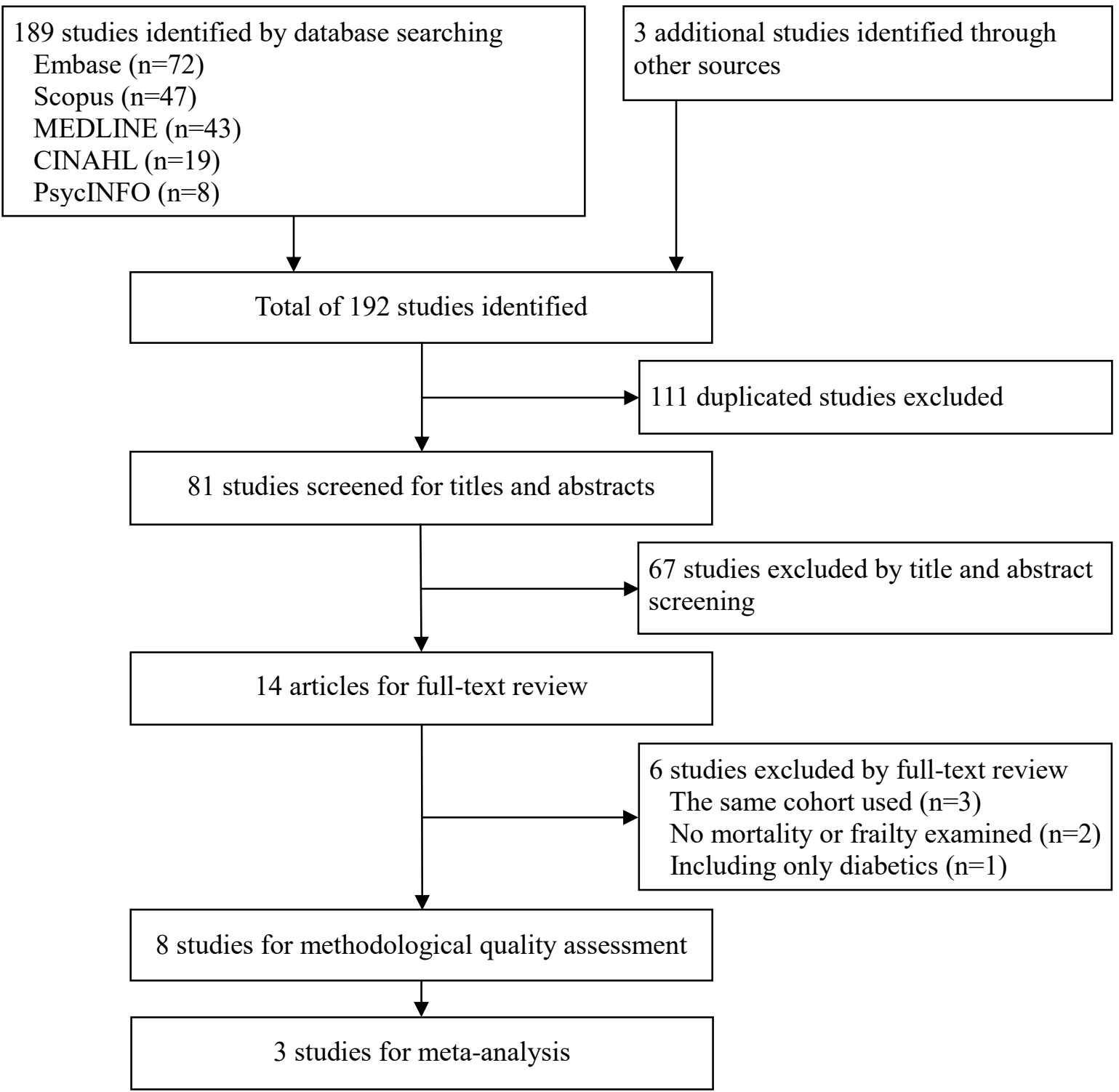


Figure 2. Forest plot of mortality risk according to frailty status based on FRAIL scale.

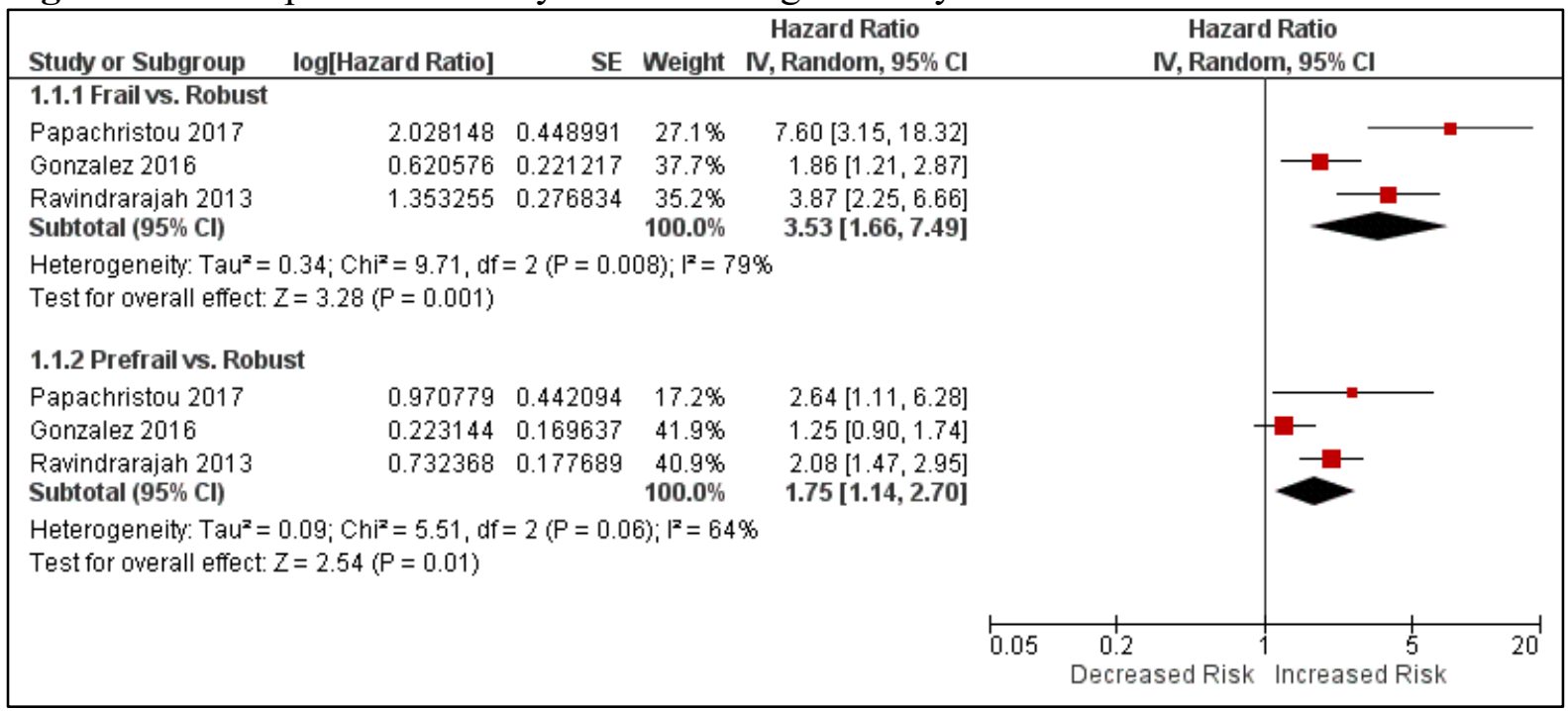

